\title{
How to recosnize skeletal craniofacial and dental types: warning signs in child snorers and risk factors for OSAS
}

\author{
C. Boehm-Hurez
}

\begin{abstract}
Dentofacial orthopedist in private practice, (Paris, France), TOSSAOS Certificate
(Odonto-Stomatologic Treatment of Obstructive Sleep Apnea Syndrome)
\end{abstract}

\begin{abstract}
In children, obstructive sleep apnea syndrome (OSAS) is common but screening is poor. The orthodontist is strategically placed within the multidisciplinary team to detect respiratory disorder and suspected OSAS.

The objective of this article is to consider indications for medical management of young patients. Parents do not always report their child's snoring, and it is up to the orthodontist to raise the question.

The orthodontist's awareness of radiological anatomy and masticatory system physiology and experience in observing the various functions in clinical examination of young patients can alert parents, guide referral to ENT or sleep medicine and allow early treatment.
\end{abstract}

\section{KEYWORDS}

Obstructive sleep apnea syndrome, children, screening, craniofacial skeletal and dental typology

\section{INTRODUCTION}

In specialized consultations for obstructive sleep disorder, ENT physicians and pneumologists are attentive to the pharyngeal anatomy and physiology implicated in snoring and apnea. Such consultations have for several years now been multidisciplinary, and orthodontists have a central role to play in screening.

ENT, pneumology and orthodontics specialists each contribute their specific diagnostic and therapeutic attitudes.
Obstructive sleep apnea syndrome (OSAS) affects children, with peak incidence between the ages of 3 and 5 years ${ }^{5,6}$.

Childhood OSAS may affect neonates as well as adolescents, and shows specific pathophysiology that differs from that found in adults and proves difficult to screen for.

Diagnosis is classically founded on polysomnography (PSG), but few children undergo this as sleep laboratory access is limited.

Address for correspondence:

Christine Boehm-Hurez - 46 Rue du Général Foy

75008 Paris - France.

E-mail: cboehmhurez@gmail.com

Article received: 15-02-2015. Accepted for publication: 14-03-2015.

This is an Open Access article distributed under the terms of the Creative Commons Attribution License (http://creativecommons.org/licenses/by/4.0), which permits unrestricted use, distribution, and reproduction in any medium, provided the original work is properly cited. 
The symptoms of OSAS are not sufficiently well known, are variable, and depend on growth stage and maturation.

Without suitable treatment, children may develop pulmonary dysfunction, neurocognitive impairment with learn- ing difficulties, mood disorder (anger, aggression), attention disorder and hyperactivity.

Daytime somnolence is not systematically reported.

Breaks in the growth curve are late warning signs.

\begin{tabular}{|c|c|c|}
\hline \multicolumn{3}{|l|}{$\begin{array}{l}\text { Full name: } \\
\text { Date of birth: }\end{array}$} \\
\hline 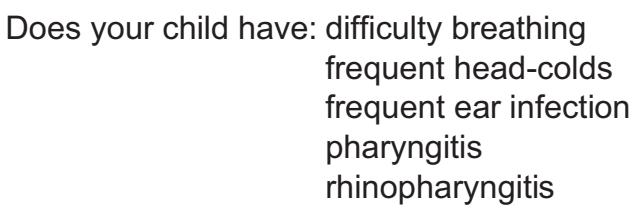 & $\begin{array}{l}\text { yes/no } \\
\text { yes/no } \\
\text { yes/no } \\
\text { yes/no } \\
\text { yes/no }\end{array}$ & \\
\hline $\begin{array}{r}\text { Has your child had the tonsils removed } \\
\text { adenoids removed }\end{array}$ & $\begin{array}{l}\text { yes/no } \\
\text { yes/no }\end{array}$ & \\
\hline $\begin{array}{l}\text { Does your child have the following signs: } \\
\text { mouth open during the day } \\
\text { sucking thumb, fingers, comforter } \\
\text { sucking lower lip } \\
\text { sleeping mouth open } \\
\text { snoring } \\
\text { rings under the eyes } \\
\text { night sweats } \\
\text { difficulty waking in the morning } \\
\text { urinating at night } \\
\text { bed wetting } \\
\text { chapped lips } \\
\text { frequent nightmares } \\
\text { sleep-walking } \\
\text { sleep-talking } \\
\text { saliva stains on pillow } \\
\text { frequent awakening at night } \\
\text { sleep apnea }\end{array}$ & $\begin{array}{l}\text { yes/no } \\
\text { yes/no } \\
\text { yes/no } \\
\text { yes/no } \\
\text { yes/no } \\
\text { yes/no } \\
\text { yes/no } \\
\text { yes/no } \\
\text { yes/no } \\
\text { yes/no } \\
\text { yes/no } \\
\text { yes/no } \\
\text { yes/no } \\
\text { yes/no } \\
\text { yes/no } \\
\text { yes/no } \\
\text { yes/no }\end{array}$ & \\
\hline \multicolumn{2}{|c|}{$\begin{array}{l}\text { Does your child push the tongue forward to speak or swallow? } \\
\text { Is your child hyperactive? } \\
\text { Does your child have difficulty concentrating at school? }\end{array}$} & $\begin{array}{l}\text { yes/no } \\
\text { yes/no } \\
\text { yes/no }\end{array}$ \\
\hline
\end{tabular}

Figure 1

Medical questionnaire. 
Interaction between obstructive respiratory disorder and craniofacial development and morphology is an important dimension of OSAS research. Certain skeletal types such as mandibular retrognathia or maxillary contraction

\section{CLINICAL WORK-UP FOR OSAS}

\section{Orthodontic consultation}

In orthodontic consultation, the importance of certain signs needs highlighting during the interview with the patient and family.

A dedicated medical questionnaire (fig. 1) establishes the patient's medical, and notably ENT, history and screens for OSAS warning signs:

- severe snoring ${ }^{9}$, apnea;

- daytime somnolence;

- daytime fatigue;

- impaired concentration;

- hyperactivity.

Overweight and obesity should be screened for.

So should allergy and asthma.

Extra-oral, intra-oral and functional examination provide preliminary information on skeletal and dental type and

\section{WHAT DOES THE LITERATURE SAY?}

\section{Predisposing facial phenotype}

A predisposing facial phenotype, involving mandibular retrusion or maxillary contraction, is found in the general population. Children presenting with obstructive respiratory disorder show significant morphological specificities are also found in the healthy population.

The orthodontist is thus an important link in the multidisciplinary chain, with a key role to play in screening for respiratory pathology in young children and adolescents who snore? ${ }^{7}$.

associated risk of onset of breathing disorder.

This clinical work-up is completed by a prescription for radiologic assessment, to be studied and interpreted by the orthodontist.

Taken together, these elements may found suspicion of OSAS.

\section{Suspected OSAS}

In case of suspected OSAS, the orthodontist refers the patient to pneumology, sleep medicine or ENT.

Clinical and radiological assessment is completed by PSG, to highlight obstructive respiratory events and rule out other sleep disorder.

Treatment associates pneumology, ENT and orthodontics.

at the skull base, maxilla and mandibular divergence.

- Guilleminault et al. described a facial phenotype found in 34\% of children with sleep-disordered breathing 8,9 .

- Rees et al. identified a particular phenotype associating micrognathia and retrognathia ${ }^{14}$. 
- Zucconi et al. confirmed this phenotype associating maxillary micrognathia, mandibular retrognathia and facial hyperdivergence ${ }^{18}$.

\section{Craniofacial typology}

Other authors reported particularities in various skeletal structures.

\section{Skull base}

- Short anterior skull base (SN distance), according to Bacon ${ }^{1,2}$ and Battage ${ }^{3}$;

- Closed skull-base angle (Ba-SN), according to Tangugsorn ${ }^{17}$ and Jamieson ${ }^{11}$.

\section{Maxilla}

- Retromaxillism, according to Lowe ${ }^{12}$, Pracharktam $^{13}$, DeBerry ${ }^{4}$ and Tangugsorn ${ }^{17}$.

- Endomaxillism, according to Pracharktam $^{13}$.

\section{Mandible}

- Retromandibulism associated with OSAS, first report by Riley ${ }^{15}$ in 1983: association found in $66 \%$ of cases.

- Retromandibulism and short mandibular body, according to Riley ${ }^{15}$, Jamieson ${ }^{11}$, Lowe ${ }^{12}$, Zucconi ${ }^{18}$, Tsuchiya and Hochban ${ }^{10}$.

- Facial hyperdivergence, according to Lowe ${ }^{12}$, Bacon ${ }^{1}$ and Jamieson ${ }^{11}$.

- Increased vertical facial dimension, according to Lowe ${ }^{12}$, Bacon', Jamieson $^{11}$ and Tangugsorn ${ }^{17}$.

\section{Hyoid bone}

- Lowered and caudal position, according to Riley ${ }^{15}$, Lowe ${ }^{12}$, Zucco$\mathrm{ni}^{18}$, Hochban ${ }^{10}$ and Battagel ${ }^{3}$.

\section{Screening factors in child and adolescent snorers}

- Hypoplasia or micromaxilla.

- Maxillary contraction or endoalveolism.

- Maxillary retrognathia.

- Mandibular retrognathia.

- Short mandibular body and ramus.

- Facial hyperdivergence.

- Short skull base - Closed skull-base angle.

- Low caudally positioned hyoid bone.

\section{HOW TO ASSESS CRANIOFACIAL AND DENTAL TYPES?}

The skeletal types described in the literature are frequently encountered in orthodontic patients presenting with snoring or disordered breathing.

There are interactions between obstructive respiratory disorders, development and craniofacial type.

The orthodontist plays a major role, as clinical examination screens for certain craniofacial and functional risk factors for obstructive respiratory pathology and may allow early treatment ${ }^{16}$.
What are the important points to note in the various extra-oral, intra-oral and functional examinations, completed by photographic and cephalometric analysis?

\section{Extra-oral and photographic study}

AP and lateral study of the face begins with clinical examination, with the patient seated in the chair, and is continued by photographic study. 

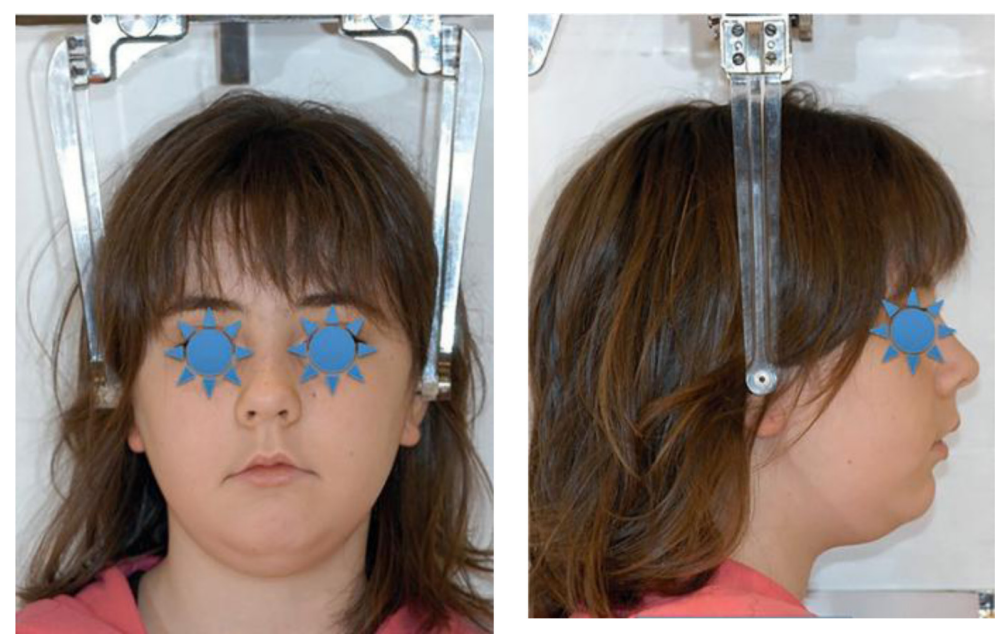

Figures 2 and 3

$A P$ and lateral photographs. Anaïs $B$.

Guilleminault ${ }^{8}$ described a specific predisposing phenotype, found in 34\% of young OSAS patients: the "adenoid facies":

- dental and skeletal class II;

- mandibular retrognathia;

- narrow, pointed chin;

- mandibular hyperdivergence ;

- long face;

- ogival hard palate;

- long soft palate.

Tracing the various planes on AP (fig.

2) and lateral photographs (fig. 3) highlights several elements.

On the AP photograph (fig. 2), we look out for:

- rings under the eyes, a sign of oral breathing;

- short, narrow nose: narrow, sometimes asymmetric nostrils, and possible septal deviation;

- thick, lateralized, chapped lips or short superior lip;

- labial non-occlusion at rest;
- relatively pronounced lip-chin groove;

- relatively well contoured chin;

- symmetry, asymmetry and height of facial levels;

- increased lower-level height, long face.

On the lateral photograph (fig. 3), to complete facial examination, we look for:

- type of profile: cisfrontal, orthofrontal or transfrontal according to the position of the upper lip and chin (cutaneous pogonion) relative to the Simon and Izard planes;

- position of the nose;

- naso-labial angle (ㅇ: $100^{\circ}$ - ô: $\left.110^{\circ}\right)$;

- position of chin, laterally;

- chin-neck distance;

- goniac angle;

- Merrifield esthetic Z line (tangent to cutaneous pogonion and most anterior point of the more protrusive lip);

- mandibular hyperdivergence;

- retromandibulism. 


\section{Intra-oral examination}

\section{Maxillary arcade (fig. 4)}

- Deep, narrow ogival palate.

- V-shaped arcade.

- Crowding.

- Vestibular version of maxillary incisors.

\section{Mandibular arcade (fig. 5)}

The mandibular arcade is very often non-congruent with the maxillary arcade, and is usually U-shaped.

\section{Adjacent tissue}

It is important to examine:

- soft palate;

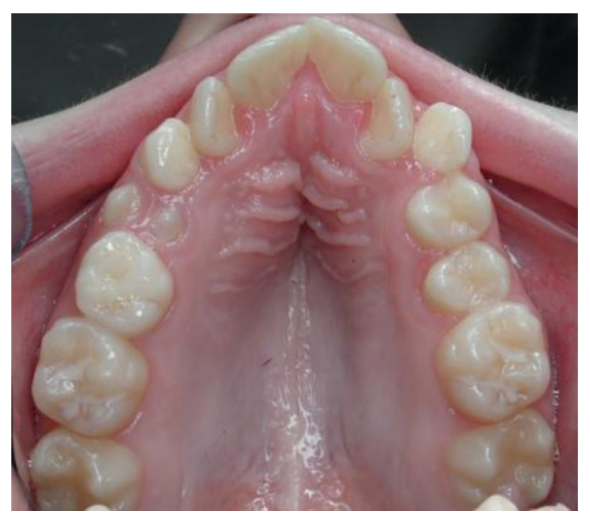

Figure 4

Maxillary arcade.

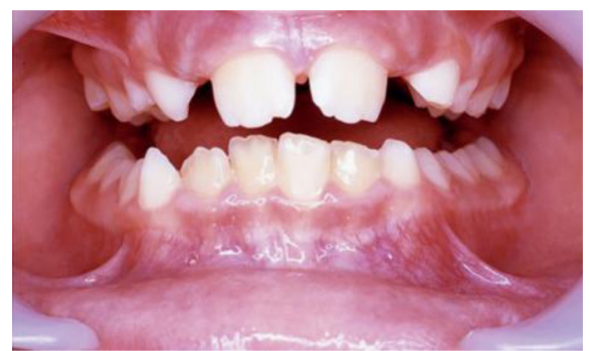

Figure 5

Non-congruence of arcades.
- palatine tonsils, which may be hypertrophic;

- volume and position of the tongue.

Various patterns of soft-tissue/skeletal or skeletal/soft-tissue relations may be found: excessive soft tissue volume or insufficient skeletal framework. It is also important to assess muscle tonus. Hypotony may be associated with soft-tissue/skeletal dysharmony.

\section{Functional examination:}

"Preventive or pre-therapeutic action on dento-maxillo-facial dysmorphia should always include screening for oral breathing." Jean Delaire.

- Position and volume of the tongue.

- Swallowing.

- Parafunctions.

- Respiration.

Dysfunction is never isolated and can induce morphologic and anatomic modifications liable to disturb or prevent various functions.

\section{Occlusion relations}

Occlusion relations are examined in 3 dimensions.

\section{Anteroposterior (fig. 6)}

Yong patients who snore and/or present with OSAS very often have Angle class II division 1 or 2 . Anterior overhang or corono-palatine incisor version may be observed.

All patterns are, however possible, including class I or III.

\section{Vertical}

Vertically, infra-occlusion or anterior supra-occlusion may be observed.

- Anterior gap (fig. 7).

- Incisor supra-occlusion (fig. 8). 

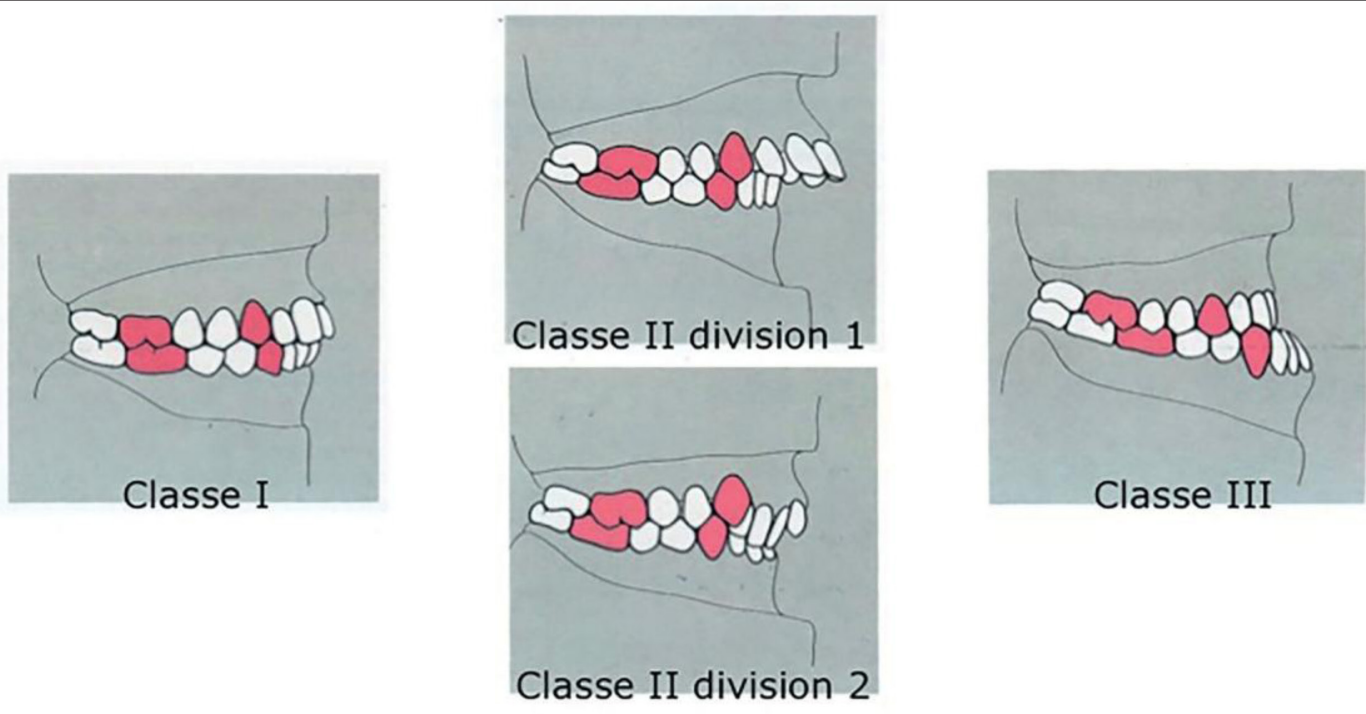

Figure 6

Anteroposterior direction.
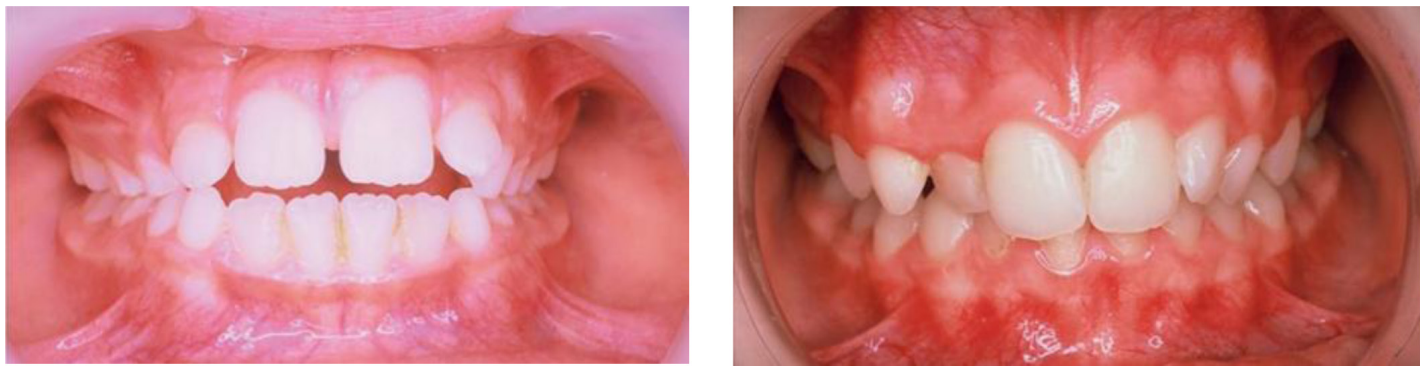

Figures 7 and 8

Vertical direction.

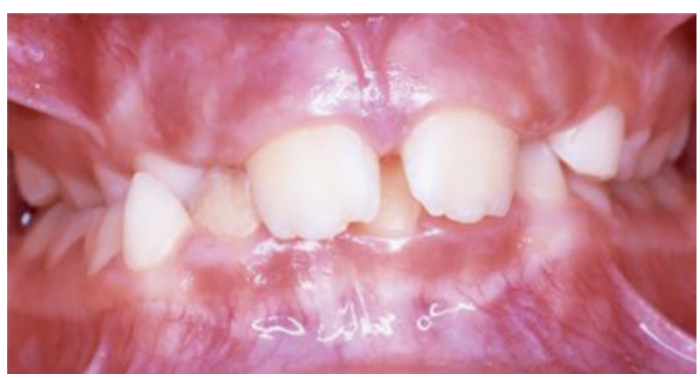

Figure 9

Transverse direction.
Transverse direction (fig. 9)

Transversally, it is important:

- to detect any deviation of the incisor center:

- to determine differential diagnosis between endoalveolism and maxillary contraction.

\section{Radiology and cephalometry}

The radiology file comprises:

- panoramic X-ray; 
- teleradiograph in occlusion;

- AP (if necessary);

- lateral;

- other views (if contributive).

Before performing cephalometry, it is important to "read" the lateral teleradiograph to screen for certain elements found in oral breathers:

- double nasal and oral entry in the oropharyngeal lumen;

- reduced oropharyngeal diameter;

- palatine tonsil and adenoid hypertrophy;

- lowered ala convexity/anterior nasal spine;

- reduced symphyseal cortex;

- mouth open, lips not together, high cutaneous/osseous pogonion;

- low tongue position;

- lowered hyoid bone/C3-C4;

- reduced frontal, maxillary and sphenoid sinus volumes;

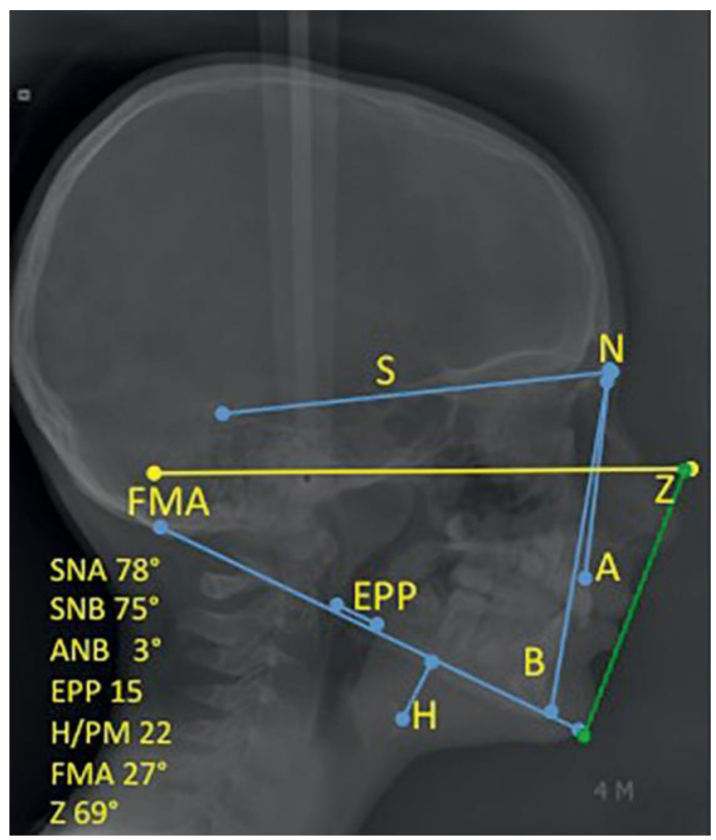

Figure 10

Tweed's cephalometric analysis, modified by Riley.
- bone narrowing in the naso-maxillary and tubercle regions.

Tweed's structural analysis (fig. 10), used here as reference, assesses skeletal anteroposterior and vertical relations.

- Anteroposterior

- Position of maxilla and mandible in the facial configuration.

- Measurement of bone base shiftSkeletal typology (Ballard classification).

Anteroposterior study focuses on the SNA, SNB and ANB angles.

Riley introduced specific measurements for OSAS:

- posterior pharyngeal space (PPE) measured in the goniac angle region;

- distance between hyoid bone and Downs' mandibular plane (HMP).

- Vertical

- Maxillary base divergence:

- normal divergence ;

- hypodivergence;

- hyperdivergence.

- Height and proportions of facial levels. Vertical study focuses on the Frankfort mandibular plane angle (FMA), anterior and posterior height, and facial height index (FHI).

While it is true that a majority of apnea patients show an increased vertical dimension, hyperdivergent skeletal pattern and oral breathing, this is not systematic, and cases of vertical insufficiency with considerable overlap and hypodivergence may be found.

Dentally, assessment focuses on:

- incisor position on lateral view (maxillary and mandibular incisor axes/ Frankfort plane);

- inter-incisor angle. 


\section{Clinical example (fig. 11a, b, c, d) (fig. 12a, b)}

a

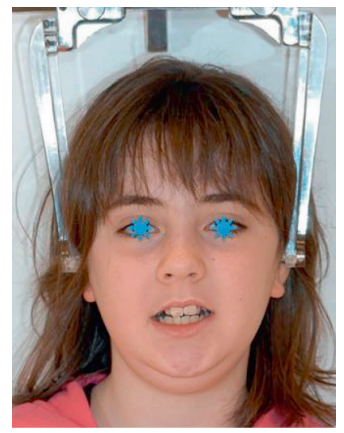

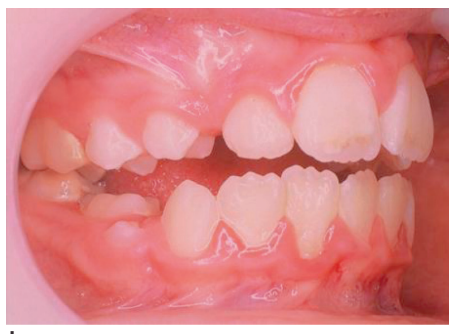

b

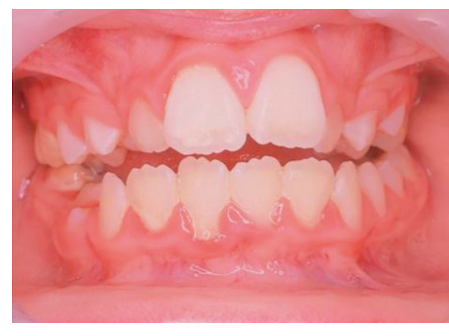

C

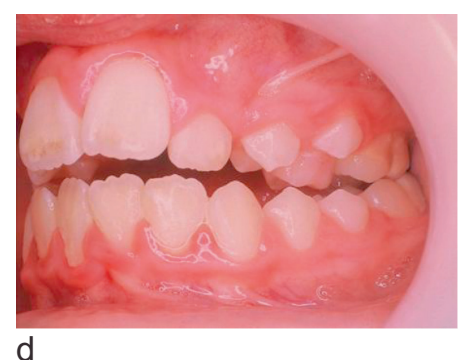

Figures $11 a, b, c, d$

Anaïs B. AP and right, frontal and left intra-oral photographs. Dental class II - anterior gap - central deviation - endomaxillism - labial non-occlusion - long face.

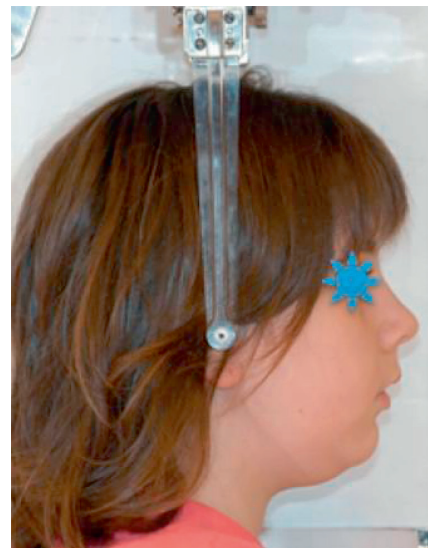

a

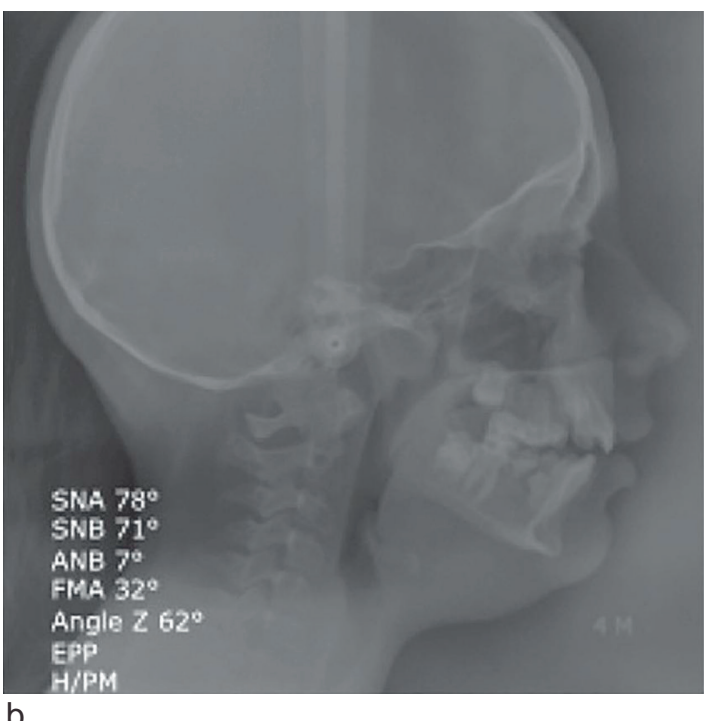

$\mathrm{b}$

Figures $12 a, b$

Anaïs B. Lateral photograph and teleradiograph. Dental class II - anterior gap - labial non-occlusion - oral breathing - long face - biretrognathia - skeletal class II - facial hyperdivergence. 
Esthetic analysis situates the lips and chin with respect to Merrifield's Z line and measures the $Z$ angle ( $Z$ line/ Frankfort plane).

\section{CONCLUSION}

Sleep is indispensable for everyone, but especially for children, being essential for growth and the development of the brain.

Before 4 years of age, 8 out of 10 children are estimated to encounter occasional sleep-related problems.

More than half under-4 year-olds snore.

There is nothing negligible about snoring, which can impact health in childhood and adolescence.

Snoring is caused by obstructed air passage, which normally runs through a series of conduits comprising nose, pharynx, larynx and trachea before reaching the lungs.

When there is an obstacle in the nose or pharynx, the child's breathing be- comes abnormal and very noisy, which often worries the parents. It may cause sleep apnea.

Childhood snoring should not be taken lightly. It may reveal a serious pathology: obstructive sleep apnea syndrome.

Craniofacial skeletal architecture influences the etiopathogenesis of OSAS.

Management of OSAS has to be multidisciplinary, and the role of the orthodontist in screening and possible early treatment of maxillary contraction and retromandibulism in children is essential.

Conflict of interest: The author declares no conflict of interest.

\section{REFERENCES}

1. Bacon W, Kuntz M, Turlot JC, Krieger J, Stierle JL. Morphologic peculiarities and major discriminants in patients with sleep apnea. Orthod Fr 1988;59 Pt 2:615-24.

2. Bacon WH, Turlot JC, Krieger J, Stierle JL. Cephalometric evaluation of pharyngeal obstructive factors in patients with sleep apneas syndrome. Angle Orthod 1990;60:115-22.

3. Battagel JM, L'Estrange PR. The cephalometric morphology of patients with obstructive sleep apnoea (OSA). Eur J Orthod 1996;18(6):557-69.

4. deBerry-Borowiecki B, Kukwa A, Blanks RH. Cephalometric analysis for diagnosis and treatment of obstructive sleep apnea. Laryngoscope 1988;98(2):226-34.

5. Cohen-Levy J. Avancée mandibulaire dans le syndrome d'apnées obstructives du sommeil : interactions avec l'orthopédie dento-faciale. Neuroscience. Université Pierre et Marie Curie - Paris VI, 2012.

6. Cohen-Levy J, Contencin P, Couloigner V. Morphologie cranio-faciale et apnées obstructives du sommeil : rôle de l'orthopédie dento-faciale. Rev Orthop Dent Fac 2009;43(3):301-16. 
7. Cohen-Levy J, Garcia R, Pételle B, Fleury B. Treatment of the obstructive sleep apnea syndrome in adults by mandibular advancement device: the state of the art. Int Orthod 2009;7(3):287-304.

8. Guilleminault C, Pelayo R, Leger D, Clerk A, Bocian RC. Recognition of sleep disordered breathing in children. Pediatrics 1996;98(5):871-82.

9. Guilleminault C, Lee JH. Does benign "primary snoring" ever exist in children? Chest 2004;126(5):1396- 98.

10. Hochban W, Brandenburg U. Morphology of the viscerocranium in obstructive sleep apnoea syndrome - cephalometric evaluation of 400 patients. J Craniomaxillofac Surg 1994;22(4):205-13.

11. Jamieson A, Guilleminault C, Partinen M, Quera-Salva MA. Obstructive sleep apneic patients have craniomandibular abnormalities. Sleep 1986;9(4):469- 77.

12. Lowe AA, Santamaria JD, Fleetham JA, Price C. Facial morphology and obstructive sleep apnea. Am J Orthod Dentofacial Orthop 1986;90(6):484-91.

13. Pracharktam N, Hans MG, Strohl KP, Redline S. Upright and supine cephalometric evaluation of obstructive sleep apnea syndrome and snoring subjects. Angle Orthod 1994;64(1):63-73.

14. Rees K, Wright A, Keeling JW, Douglas NJ. Facial structure in the sudden infant death syndrome: case control study. BMJ 1998;317(7152):179-80.

15. Riley R, Guilleminault C, Herran J, Powell N. Cephalometric analyses and flow volume loops in obstructive sleep apnea patients. Sleep 1983;6(4):303-11.

16. Seailles T, Couloigner V, Cohen-Levy J. Savoir dépister le Syndrome d'Apnées Obstructives du Sommeil (SAOS) de l'enfant. Rev Orthop Dent Fac 2009;43(3):261-78.

17. Tangugsorn V, Skatvedt O, Krogstad O, Lyberg T. Obstructive sleep apnea: a cephalometric study. Part II. Uvulo-glossopharyngeal morphology. Eur J Orthod 1995;17(1):57-67.

18. Zucconi M, et al. Craniofacial modifications in children with habitual snoring and obstructive sleep apnea: a case-control study. Eur Respir J 1999;13(2):411-7. 